\title{
Lexical Representation of Knowledge about a Human Being in English
}

\author{
Tatiana Golechkova \\ National Research University Higher School of Economics
}

\begin{abstract}
Correspondence concerning this article should be addressed to Tatiana Golechkova, English Language Department for Economic and Mathematical Disciplines, National Research University Higher School of Economics, 26 Shabolovka St., Moscow, Russian Federation, 119049. E-mail: tgolechkova@hse.ru
\end{abstract}

\begin{abstract}
This paper presents the research in the sphere of lexical representation. On the premise that word meaning offers insights into conceptual knowledge stored in the mind, we have analyzed the semantics of the set of synonyms denoting a human being without reference to gender, age, occupation or peculiarities of personality and without any evaluation of the referent. These lexical items are person, individual, human being, and one of the meanings of man and personality. Use of etymological, dictionary, derivational, collocation, context analysis and conceptual modelling enabled us to build a list of conceptual components that comprise the knowledge about a human being represented in the English language. To date, the conceptual models used to visualize knowledge do not seem applicable to visualizing knowledge about a human being; therefore, we could only formulate the main features that are characteristic of this knowledge in the English world-view.
\end{abstract}

Keywords: cognitive model, words denoting a human being, semantic component, synonyms

Conceptual knowledge, the ways in which it is stored in the mind, the mechanisms that enable the processes of activating this knowledge at appropriate times and in relevant situations have long been the focus of scientific attention. One of the means to access this knowledge and study these processes is offered within the domain of Cognitive Linguistics. It has become a widely recognized notion that language in general and lexical units in particular serve as linguistic representation of this knowledge (Evans \& Green, 2009; Croft \& Cruse, 2004; Kubryakova, 2012), providing the means to study this knowledge.

Knowledge and mental activity are produced by people and one of the major reasons for this is a desire to understand the nature of a human being, his/her place and role in the world. From the cognitive point of view, language will be an invaluable source of such information. Therefore, in our research we attempt to build a model of the knowledge that has been accumulated about a human being in the course of history, processed within the mind and then represented linguistically in vocabulary items.

The words that represent this knowledge are the synonyms denoting a human being. However, this is a very large lexical set capturing a whole range of human characteristics. To focus on the basic features, it was necessary to limit the items under research to those denoting a human being without reference to the gender, age, occupation or peculiarities of personality and without any evaluation of the referent. The words that fulfill these criteria are the following: person, human being, man, individual, personality. Another important point is that most of these words are polysemantic, but in this research only the meaning 'a human being' and the contexts where this meaning is realized were selected and studied.

\section{Materials and Methods}

When studying the selected set of synonyms, we followed a research framework developed by Elena G. Belyaevskaya (1992) and successfully implemented by a large number of researchers. This approach makes it possible to reconstruct conceptual knowledge represented by lexical items. Belyaevskaya proposed to start by looking at the etymology of a word, paying 
special attention to its origins, constituents and their meanings, and the development of its semantics and use.

Once the etymology has been established, contemporary use of the vocabulary is thoroughly studied, which involves a range of methods and techniques. The first one is analysis of available dictionary definitions and formulation of semantic components that comprise the dictionary meaning of the word. The lexical item is compared and contrasted with its synonyms to further highlight these components. At this stage, derivational models are also studied.

When a list of semantic components is obtained, it is finalized with the help of co-text and context analysis. While the former presupposes a study of immediate collocation in preposition or postposition of the item in question, the latter takes a broader look at the text extract as whole, identifying peculiarities of word meaning that are realized on the contextual level. This analysis, especially that of collocates, is facilitated by Corpus Linguistic methods that enable automated data collection and processing (Gries, 2006). Corpus research tools and their application to semantic analysis and cognitive modelling within this approach are described by Ekaterina Golubkova (2009) and Tatiana Golechkova (2012).

The final stage involves building a cognitive model representing the mental structure of knowledge that is verbalized in the corresponding lexical items. Cognitive models in this case are understood as coherent bodies of perceptual and subjective experience types (Evans, 2010) that help formalize and visualize conceptual knowledge. This research framework appears universal in the sense that it can be used effectively for different types of vocabulary, including lexical items denoting a human being.

\section{Results}

\section{Semantics of English Words Denoting a Human Being}

As a result of etymological, dictionary, derivational, collocation and context analysis we were able to describe the semantic structure represented by synonyms denoting a human being. We have studied 3 etymology dictionaries, 8 contemporary English dictionaries and over 1500 examples of the use of the items both from fiction or non-fiction, most of which were offered by the British National Corpus (BNC) and Corpus of Contemporary American (COCA).

Etymological analysis has shown that the synonyms denoting a human being have experienced both changes in their dominant meaning and addition of other semantic components. It could prove that corresponding conceptual structures are flexible and dynamic, which may seem counterintuitive given the prominently solid position of the human being in the world-view. The best example is the word man, which is the only Germanic word in the set; it was originally used as 'a male human being', then it acquired the meaning of a gender-neutral human being and later returned to its original meaning [dictionary]. The dynamic nature of this vocabulary set is also reflected in the fact that individual developed the meaning 'a human being' first in the colloquial speech and then it entered specialized formal legal or academic English.

Dictionary analysis enabled us to identify and formulate semantic components that comprise the semantics of the analyzed synonyms. The component bringing all these words together is 'species Homo sapiens', which represents the knowledge about people as biological species and the features that differentiate a person from other animals, i.e. their articulate speech, upright stance and mental development. A separate component comprises the information about what people usually look like and their traits of character, or 'personality and appearance'. These could be either typical of the species or particular of its certain representative. Apart from looks and behavior, people normally develop in society and are therefore seen as social beings, which entails not only specific features, but also certain roles and responsibilities. The following components capture and reflect in the semantics the social aspect of a person: 'member of a socium', 'possesses socio-cultural features of a socium', 'has rights and responsibilities' and 'possesses social significance'.

Mentioned above are what we could call meaningful or informative human features that are represented in the semantics of words. Apart from this, there are several abstract components that describe intangible aspects not particular of the species. The first ones identify whether the referent is a member of a class or vice versa stands out from a class (components 'belongs to a class (classification)' and 'is differentiated from a class (individualization)'). If a person is viewed as a class member, he/she possesses characteristics that make it possible to refer him/her to the class, which can make him/her an average recognizable representative (component 'typical of a class'). On the other hand, the referent can have a feature that makes him/her different from other class members, in this case he/she 'is differentiated according to a criterion'.

The synonyms denoting one human being have been studied and the plural forms or words referring to groups of people were beyond the scope of the research. Therefore, some lexical items possess a clear 
Table 1

Semantic structure of synonyms denoting a human being

\begin{tabular}{llll}
\hline Lexical item $\rightarrow$ & $\begin{array}{l}\text { Human } \\
\text { being }\end{array}$ \\
\hline Semantic component $\downarrow$ & Person & Individual & Man \\
\hline Species Homo sapiens & & Personality \\
\hline $\begin{array}{l}\text { Pelongs to a class } \\
\text { (classification) }\end{array}$ &
\end{tabular}

\begin{tabular}{lllll}
\hline $\begin{array}{l}\text { Is differentiated from a class } \\
\text { (individualization) }\end{array}$ & 0 & 0 & 0 \\
\hline Member of a socium & 0 & 0 & 0 \\
\hline
\end{tabular}

Is typical of a class $\bigcirc$

Is differentiated according to a criterion

Is singular, one

(2) 0

(2) 0

Has rights and responsibilities

Possesses social significance

O

(?)

Is evaluated positively

Possesses socio-cultural

features of a socium

meaning of singularity or oneness (component is singular, one').

The last of the identified semantic components is connected with evaluation of the referent. Although we excluded from the research all words that have strong overtly positive or negative connotations as well as pronounced evaluation of the referent, the lexical item personality carries the idea that the person in question can be seen as a beneficial member of the socium and therefore has the component 'is evaluated positively' in its semantic structure.

While dictionary research, along with context and cotext analysis, helped to identify and formulate the components that comprise the semantics of the synonyms, a more careful study of contexts and corpus methods enabled the building of the semantic structures of each word. These structures cannot be represented as lists of semantic components, as within lexical item each the meanings carry different weight, in other words, some are at the top of the hierarchy and others are at the bottom (Malyar,

2001). The table below summarizes the findings of our semantic research. The circles represent the presence of a semantic component in the semantic structure of a corresponding word and double circles represent the dominant component at the top of the semantic hierarchy of each lexical item.

The semantic information presented in the form of a table makes it possible not only to analyze individual word meanings, but also to compare and contrast the lexical items. On the premise that semantic structure of a word or set of words is the representation of corresponding conceptual knowledge, we can now proceed to conceptual modelling.

\section{Selecting an Efficient Cognitive Model}

While most researchers focus on explaining and representing the process of meaning construction either in context or outside it (Lakoff \& Johnson, 2008; Fauconnier \& Turner, 2006 and others), there are only a few models that help present the result of 
these processes. Among the most common and wellestablished ones are frames, semantic descriptions and qualia-structures. Each of them will be examined in more detail and their applicability to describing the conceptual knowledge about a human being will be analyzed.

One of the earliest and currently most elaborate models is frame. Originally introduced by the computer scientist Marvin Minsky and defined as a data structure for representing a stereotyped situation (Minsky, 1975), it then found its way into Linguistics in the works of the linguist Charles Fillmore. He expanded the notion applying it to semantic research by stating that a frame is a set of related lexical units (linguistic variants), which describe a recurring scenario (Fillmore, 1982). Frames are described as structures similar to networks that consist of nodes, or slots, and relations between them. The slots can be of two types: fixed slots which include the information that is always typical of situations of a certain kind; the others are filled with contextual information depending on the instance of frame activation in a communication act. A frame is usually verbalized through a set of lexical units. Currently, it is used to represent not only situational knowledge, but also knowledge about objects (Bondarchuk, 2011). However, these objects tend to include a wide variety of items, i.e. variants and criteria, according to which the variants are verbalized.

Frames are believed to possess a rigid and clear structure, which can be both an advantage and a drawback. In the case of representing conceptual knowledge about a human being, it appears to be a disadvantage, since, as shown above, this knowledge is flexible and only partly falls into a limited set of slots related to human characteristics. There are a few other reasons why frame does not seem efficient for visualizing knowledge about a human being. First, this data is not stereotypical, second, it is difficult to identify clear-cut relations between data items which appear complex and multi-level, third, the knowledge about a human being is dynamic and hence does not fully fit the rigid structure of a frame.

Another very commonly used model for representing conceptual knowledge is semantic descriptions which were introduced and formalized by Anna Wierzbicka. She proceeds from the idea that the most complex concepts can be presented in a simpler operational form with various related concepts arranged around central ones. This approach helps to formulate clear definitions for lexical items. These definitions tend not to include all the available knowledge about an object or notion, but focus on basic essential features, which makes them easy to operate and store in the mind. An example could be the class of objects Animal, the components of which are defined through Habitat, Size, Appearance, Behavior, Relations to people (Wierzbicka, 1985). These building blocks of definitions are established by analyzing general experience, features and functions of real-life objects and verbalized as well as non-verbalized knowledge about them.

Qualia structure -is a representational framework developed by James Pustejovsky within a broader model for studying and capturing relationships between items on a syntactic level. The structure proposes to analyze the meaning of lexical items and the related conceptual knowledge in terms of four aspects: formal, constitutive, telic, agentive. The formal aspect distinguishes an object within a larger domain based on its appearance and other external features. The constitutive aspect identifies relations between the object and its constituents, the telic aspect states the purpose and the function of the object and finally, agentive refers to the origin of the object (Pustejovsky, 1995).

The previous two models do not appear efficient for representing the knowledge about a human being. The main reason is the nature of the lexical items denoting a human being: they possess a broad meaning including abstract knowledge, which is not reflected either in Wierzbicka's or in Pustejovsky's frameworks. Indeed, they tend to be suitable for modelling concrete concepts, as they mainly include basic perceptual knowledge, such as appearance, constituent components, behavior. In addition, the vocabulary under analysis requires representation of evaluative elements, background information and associations, which are not reflected in any of the frameworks.

\section{Discussion}

\section{Knowledge Representation in the English Synonyms}

Having assessed various cognitive models, we may conclude that none of them appear efficient for representing the conceptual knowledge about a human being stored in English vocabulary. However, the results of the semantic analysis help to reconstruct conceptual components of the mental system. Although this knowledge does not seem to lend itself to structural representation, these components show some trends and features typical of this particular stored knowledge.

First, the components clearly fall into three key pairs having opposing meanings with others related to them:

- Species Homo sapiens or a social being; 
- Belongs to a class (classification) or is differentiated from a class (individualization);

- Is singular/one or is a member of a class.

Depending on the choice of one of these alternatives, particular information about a human being is highlighted and a corresponding lexical unit is chosen in speech. The first opposition 'biological species vs social being' is particularly important for the mentality of English speakers, which is reflected in the fact that each meaning in this opposition is verbalized in a dedicated lexical item, human being and person respectively, rather than being a component along with others in the semantic structure of a word. In the Russian language, by contrast, one item человек (chelovek) incorporates the two components.

The opposition 'classification vs individualization' is realized in all the synonyms: human being, man (classification) and person, individual, personality (individualization). Representing two abstract ideas of reference to a class or differentiation from it, this opposition appears important for identifying the difference between two similar synonyms man and person. While the former classifies the referent, the latter individualizes it.

The last opposition 'singularity vs plurality' requires a further explanation. Our research has shown that the idea of 'plurality' in this case is not the grammar concept of 'being more than one', but belonging to a group, organization etc. This conceptual knowledge relates to the semantics of the words man and human being. It means that man and human being describe any person, whereas individual and personality denote a single person opposed to a group of people (e.g. class, company, family). The significance of the idea of singularity and the corresponding importance of the opposition is shown by the fact that the lexical item individual is neutral in register and relatively common. It is less common in Russian, as exampled by the Russian equivalents индивидуум (individuum) and физическое лицо (fizicheskoe litso), which are narrowly specialized and formal.

The second peculiarity of the conceptual knowledge about a human being that may be culture-specific for the English-speaking community is the prominence of some of the components when compared to others (Evans, 2013). According to our research, the following conceptual knowledge appears significant for the English language: 'has rights and responsibilities', 'possesses social significance', 'possesses sociocultural features of a socium' and 'member of a socium'. The last two are realized in the semantics of the word man, the first two in separate meaning of polysemantic lexical items individual ('has rights and responsibilities') and personality ('possesses social significance'). This highlights the importance of this conceptual knowledge for the culture. In other words, in the English world-view the idea of someone's belonging to society with its relations and regulations, being part of a culture, customs, traditions, attitudes and lifestyles prevails over the biological speciesrelated features, which is illustrated in the ways this information is verbalized in the words person, man, individual, personality on the one hand and human being on the other. Unlike English, the Russian language does not have a dedicated lexical item for expressing the social aspect of a person.

\section{Conclusion}

The study of English lexical items denoting a human being has helped to uncover the conceptual basis for naming a human being through reconstructing and analyzing conceptual knowledge that underlies the semantics of the corresponding nouns person, human being, individual, man and personality. The main research findings are the following:

1) conceptual knowledge about a human being is a system that only partly lends itself to existing conceptual models;

2) conceptual knowledge about a human being is a flexible and dynamic system, which satisfies the needs of the English-speaking society by adapting lexical items and their meaning to social changes;

3) conceptual knowledge about a human being foregrounds the social aspect of a human being, his role and function in society;

4) conceptual knowledge about a human being is based on six opposing components: 'biological species vs social being', 'classification vs individualization', 'singularity vs plurality';

5) conceptual knowledge about a human being is characterized by several well-formed components each verbalized in a lexical item: individual ('has rights and responsibilities'), personality ('possesses social significance'), man ('possesses socio-cultural features of a socium' and 'member of a socium').

These findings further our understanding of semantic representation and determine English culture-specific features of conceptual knowledge about a human being. It is particularly useful and highly beneficial for language teaching, as this information offers an insight into word meaning, collocation and general use (Evans \& Tyler, 2004) In addition, availability of the mental system will help greatly when translating from and into English.

The results of the research once again demonstrate the efficiency of semantic research in cognitive modelling, at the same time, analysis of the knowledge 
about a human being has determined certain limitations. There is a need for further research into cognitive models and methodologies for building them, as existing ones are efficient for describing the information represented by concrete nouns rather than more complex abstract notions and more general concepts. The models should enable representation of the flexibility and social adaptability of the knowledge, as well as present the space for incorporating potential further modifications and development of the corresponding concept or referent, which is bound to be reflected on both semantic and cognitive levels.

\section{References}

Belyaevskaya, E. G. (1992). Semanticheskaya struktura slova $v$ nominativnom $i$ kommunikativnom aspektah [The semantic structure of the word in the nominative and communicative aspects] (Unpublished Doctoral thesis). Moscow State Linguistic University, Moscow, Russia.

Bondarchuk, G. G. (2011). Kognivno-semioticheskie osnovaniya razvitiya kategorii predmetnih imen $v$ anglijskom yazike (na materiale anglijskih naimenovaniy odezhdi) [Cognitive and semiotic basis of development of the category of substantive names in the English language (on the material of words denoting clothes)] (Unpublished Doctoral thesis). Moscow State Linguistic University, Moscow, Russia.

Croft, W., \& Cruse, D. A. (2004). Cognitive linguistics. Cambridge, UK: Cambridge University Press.

Evans, V., \& Green, M. (2009). Cognitive linguistics: An introduction. Edinburgh, UK: Edinburgh University Press.

Evans, V. (2010). On the nature of lexical concepts. Belgrade Journal of English Linguistics and Literature Studies, 2, 11-46.

Evans, V. (2013). Metaphor, lexical concepts and figurative meaning construction. Cognitive Semiotics, 5(1-2), 73-107.

Evans, V., \& Tyler, A. (2004). Applying cognitive linguistics to pedagogical grammar: The case of over. In M. Achard \& S. Niemeier (Eds.), Cognitive Linguistics, Second Language Acquisition, and Foreign Language Teaching (pp. 257-280). Berlin,
Germany: Mouton de Gruyter.

Fauconnier, G., \& Turner, M. (2006). Mental spaces. Conceptual integration networks. In D. Geeraerts (Ed.), Cognitive linguistics: Basic readings (pp. 303371). Cambridge, UK: Cambridge University Press.

Fillmore, Ch. J. (1982). Frame semantics. In The linguistics in the morning calm (pp. 111-138). Seoul, South Korea: Hanshin Publishing.

Golechkova, T. Yu. (2012). Ispolzovanie korpusnih dannih pri issledovanii diskursivnih harakteristik naimenovaniy cheloveka $\mathrm{v}$ angliyskom yazike [Using corpus-retrieved data for studying discourse features of words denoting a human being in the English language]. Vestnik Moskovskogo Gosudarstvennogo Lingvisticheskogo Universiteta, Series Language Studies, 5(638), 83-89.

Golubkova, E. E. (2009). Korpusnie dannie pri izuchenii semantiki slovosochetaniy ustoichivogo haraktera [Corpus-retrieved data for studying the semantics of fixed word combinations]. Vestnik Moskovskogo Gosudarstvennogo Lingvisticheskogo Universiteta, Series Language Studies, 572, 30-37.

Gries, S. (2006). Corpus-based methods and cognitive semantics: The many senses of to run. In S. Th. Gries \& A. Stefanowitsch (Eds.), Corpora in cognitive linguistics: Corpus-based approaches to syntax and lexis. Trends in linguistics (Vol. 172, pp. 57-100). Berlin, Germany: Mouton de Gruyter.

Kubryakova, E. S. (2012) V poiskah suschnosti yazyka: Kognitivnye issledovania [Searching for the nature of the language: Cognitive research]. Moscow, Russia: Znak.

Lakoff, J., \& Johnson, M. (2008). Metaphors we live by. Chicago, IL: University of Chicago Press.

Malyar, T. N. (2001). Konceptualizacia prostranstva $i$ semantika angliyskih prostranstvennih predlogov $i$ narechiy [Conceptualization of space and semantics of English prepositions and adverbs denoting space] (Unpublished doctoral thesis). Moscow State Linguistic University, Moscow, Russia.

Minsky, M. (1975) A framework for representing knowledge. In P. H. Winston (Ed.), The Psychology of Computer Vision (pp. 211-277). New York, NY: McGraw-Hill.

Pustejovsky, J. (1995) The generative lexicon. Cambridge, MA: MIT Press.

Wierzbicka, A. (1985) Lexicography and conceptual analysis. Ann Arbor, MI: Karoma Publishers. 